\title{
Numerical Simulation and Experiment for Thermal-mechanical Coupling of Disc Brake
}

\author{
Jian Zhang ${ }^{1, \text { a }}$, Jiajun $\mathrm{Du}^{1, \mathrm{~b}}$, Yongmei Zhu' ${ }^{1}$, Xuelong $\mathrm{Tan}^{2}$ \\ ${ }^{1}$ Jiangsu University of Science and Technology, Zhenjiang, 212013, China \\ ${ }^{2}$ Road Vehicles in Jiangsu Province Key Laboratory of New Technology Application \\ aemail: zhjian127@163.com, bemail:dujiajun93@163.com
}

Keywords: disc brake; finite element method; thermal-mechanical coupling; thermal fatigue; crake

\begin{abstract}
Based on the tensile and compression experiments of the materials of brake disk and friction plate of disk brake, the elastic modulus and Poisson's ratio of brake disk and friction plate were measured respectively. In order to analyze the temperature and stress fields of brake disk and friction plate, the 3D model of brake disc and friction plate were established, then using Ansa for mesh division and utilizing the finite element method about the function of thermal-mechanical coupling simulation to finish that. What's more, combined with the simulation of temperature and stress fields, experiment of the temperature field about brake disc was conducted to explore the reasons for the formation of thermal fatigue. The result shows that the generation of thermal fatigue of brake disk is affected by the surface temperature gradient and the temperature's changing frequency, and the cracks were mainly concentrated in the annular and high temperature areas.
\end{abstract}

\section{Introduction}

Disc brake is one of the important parts of the vehicle, which has the advantages of simple structure, stable braking performance and so on, and it is used widely in the vehicle industry [1]. The process of vehicle braking is a dynamically thermal-structure coupling problem which is complex. When the brake disc and friction plate work, they generate a large number of heat, making the temperature rise on the local surface of brake disk, and leading to local deformation and the unfairly distribution of contact pressure on the surface of the brake disc, so the brake disc will be under the damage of thermal fatigue. This case will not only reduce the service life of disk brake, but also bring the security risks to the vehicle [2].

Finite element analysis is one of the main methods to analyze and verify the brake disc and friction plate at present. In order to analyze the problem of temperature and stress fields, Chenghui Gao [3] and others established the mathematical model and analysis method of transient thermal-mechanical coupling of disc brake; Jishan Li [4], who established the 3D symmetric finite element model of brake disc to discuss the problem of the temperature and stress fields; the temperature field of the brake disc under high speed braking was analyzed by Haiyan Zhao [5], and she also obtained the distribution law of transient temperature field. However, the references above were only theoretical analysis and did not take the continuous braking condition into consideration, so the results remained to be discussed.

Therefore, the disc brake of 24.5 inches was taken as the object, and analyzed it under thermal boundary condition and displacement boundary condition. Meanwhile, in order to acquire the distributions of temperature and stress fields under continuous braking condition, using Pro-E to establish 3D model and using Ansa, ABAQUS to analyze finite element models of brake disc and the friction plate, which can provide evidences to solve the problem of thermal fatigue and increase the service life of the disc brake.

\section{Experiments}

Mechanical experiments of brake disc and friction plate

According to the tensile and compression experiments, the elastic modulus and Poisson's ratio of 
brake disc and friction plate can be measured from $25^{\circ} \mathrm{C}$ to $500^{\circ} \mathrm{C}$. The cylindrical specimen material of brake disc was grey cast iron(HT250), such as Fig 1 (a), when the experiments carried out, the standards were according to the 'Metal Compression Experiment Method GB/T7314-87'; the dumbbell-like specimen material of friction plate was resin matrix composite, such as Fig 1 (b), when the experiments carried out, the standards were according to the 'Criteria for Performance of Fiber Reinforced Plastics GB/T1447-2005'. All of these experiments were done at the universal tensile and compression experiment machine, the elastic modulus and Poisson's ratio of the brake disc and the friction plate were measured at $25^{\circ} \mathrm{C}, 100^{\circ} \mathrm{C}, 200^{\circ} \mathrm{C}, 300^{\circ} \mathrm{C}, 400^{\circ} \mathrm{C}$ and $500^{\circ} \mathrm{C}$ respectively, and the results of the experiments were shown in Table 1.

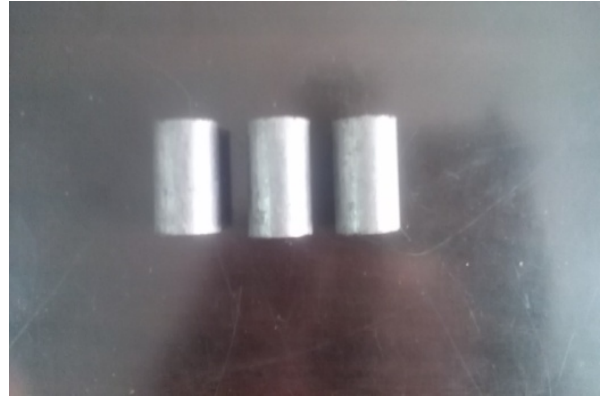

(a) Cylindrical specimen of brake disc

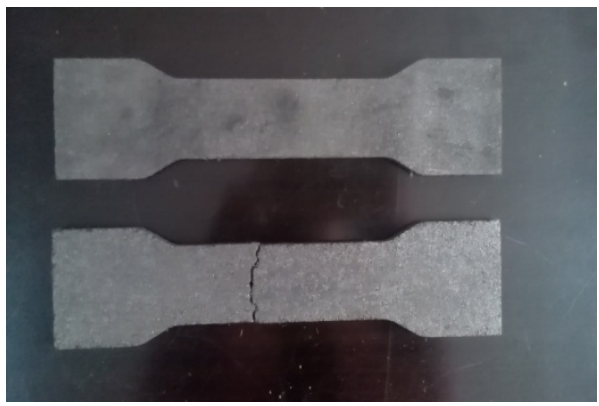

(b) Dumbbell-like specimen of friction plate

Fig.1 Material experiments

Table.1 The elastic modulus and Poisson's ratio of brake disc and friction plate at different temperature

\begin{tabular}{|l|c|c|c|c|c|c|c|}
\hline Object & Temperature & $25^{\circ} \mathrm{C}$ & $100^{\circ} \mathrm{C}$ & $200^{\circ} \mathrm{C}$ & $300^{\circ} \mathrm{C}$ & $400^{\circ} \mathrm{C}$ & $500^{\circ} \mathrm{C}$ \\
\hline \multirow{2}{*}{$\begin{array}{l}\text { Brake } \\
\text { disc }\end{array}$} & $\begin{array}{c}\text { The elastic } \\
\text { modulus } \\
/ G P a\end{array}$ & 125 & 120 & 120 & 114 & 110 & 105 \\
\cline { 2 - 8 } & Poisson's ratio & 0.3 & 0.3 & 0.3 & 0.3 & 0.298 & 0.298 \\
\hline \multirow{2}{*}{$\begin{array}{l}\text { Friction } \\
\text { plate }\end{array}$} & $\begin{array}{c}\text { The elastic } \\
\text { modulus } \\
/ G P a\end{array}$ & 2.2 & 1.9 & 1.8 & 1.5 & 1.3 & 0.9 \\
\cline { 2 - 8 } & Poisson's ratio & 0.25 & 0.25 & 0.25 & 0.25 & 0.25 & 0.249 \\
\hline
\end{tabular}

\section{Experiments of temperature field}

The experiments of temperature field were done in Jiangsu HengLi Brake Manufacturing Company, the machine's measuring range of temperature is from $-40^{\circ} \mathrm{C}$ to $1500^{\circ} \mathrm{C}$, and real-time temperature can be acquired by infrared thermal image. At first, put the disc brake of 24.5 inches into inertia experimenting counter, then gave $1.2 \mathrm{Mpa}$ pressure to the air-cell of disc brake, and set the initial velocity and braking deceleration at $60 \mathrm{~km} / \mathrm{h}$ and $-4.5 \mathrm{~m} / \mathrm{s}^{2}$. Finally, measured the temperature of friction interface 10 times continuously and every time interval was $25 \mathrm{~s}$, and used the software of NEC to export the distributing disciplinarian of the temperature about the surface of brake disc.

\section{Mathematical Model}

For example, a simplified 3D finite element model was established, such as Fig 2 (a), then used the finite element analysis software ANSA to partition the brake disc and friction plate, such as Fig 2 (b). The material of brake disc is HT250, its density, specific heat, thermal conductivity and thermal expansion are $7200 \mathrm{~kg} / \mathrm{m}^{3}, 453 \mathrm{~J} / \mathrm{kg}^{\circ} \mathrm{C}, 48 \mathrm{~W} / \mathrm{m}^{\circ} \mathrm{C}$ and $4.39 / 10^{-6} \mathrm{~K}^{-1}$, and its elastic modulus and Poisson's ratio can be found in the Table 1 ; the material of friction plate is resin matrix composite, its density, specific heat, thermal conductivity and thermal expansion are $1550 \mathrm{~kg} / \mathrm{m}^{3}$, $1200 \mathrm{~J} / \mathrm{kg}^{\circ} \mathrm{C}, 0.9 \mathrm{~W} / \mathrm{m}^{\circ} \mathrm{C}$ and $10 / 10^{-6} \mathrm{~K}^{-1}$, and its elastic modulus and Poisson's ratio can be found in the Table 1.The two models were divided by six hexahedrons and eight nodes units, and 
the total grid number was 15781 and the number of nodes was 13145.

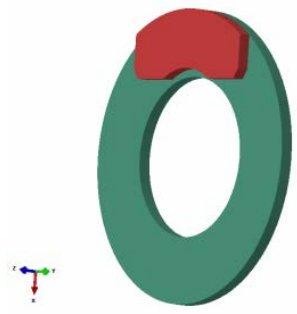

(a)3D model

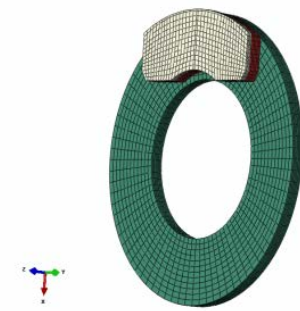

(b) grid model

Fig.2 Finite element model of disc brake

\section{Boundary Conditions}

\section{Thermal boundary condition}

A large amount of heat energy was generated during the braking process of the disc brake, and the heat energy was released by three ways: heat conduction, heat convection and heat radiation. In this paper, only heat conduction and thermal convection are under consideration.

1)Heat distribution ratio

According to the document [6], the expression of heat distribution coefficient can be obtained, and bring the parameters of the material about brake disc and friction plate into the formula, the result can be received as the formula (1):

$\gamma=\frac{q_{d}}{q_{f}}=\left(\frac{k_{d} c_{d} \rho_{d}}{k_{f} c_{f} \rho_{f}}\right)^{1 / 2}=9.6$

In the type: $k_{d} 、 c_{d} 、 \rho_{d}$ are the thermal conductivity, specific heat and density of the brake disc; $k_{f} 、 c_{f} 、 \rho_{f}$ are the thermal conductivity, specific heat and density of the friction plate.

As a result, the proportion of heat energy which absorbed by the friction plate can be concluded as the formula (2):

$$
f_{f}=1 /(1+\gamma)=0.1
$$

2) Coefficient of convective heat transfer

The braking device installs in the box body which is sealed, and the surface of the brake disc is exposed to the air. According to the coefficient of natural convective heat transfer in document [7], during the process of the braking, the coefficient of convective heat transfer of brake disc can be calculated the formula (3):

$$
h_{d}=\left\{\begin{array}{l}
7.839 \omega^{0.55} 0 \leq \omega \leq 17.14 \\
4.873 \omega^{0.8} \omega \geq 17.14
\end{array}\right.
$$

From the results of the document [8], it shows that at the same speed, temperature has little effect on the coefficient of convective heat transfer, which can be ignored. However, with the increase of the rotating speed of the brake disc, the coefficient of convective heat transfer increases relatively. Meanwhile, the position of the nodes has influence on the coefficient of convective heat transfer. After taking the influence of temperature, the speed of the brake disc and the position of nodes into consideration synthetically, the modified analytic formula can be obtained the formula (4):

$$
h_{d}=\left\{\begin{array}{l}
10.974 \omega^{0.55} 0 \leq \omega \leq 17.14 \\
5.361 \omega^{0.8} \omega \geq 17.14
\end{array}\right.
$$

\section{Displacement boundary condition}

In order to simulate the braking process of the disc brake accurately, defined the inner ring of brake disk with motion coupling constraints, and the constraint of reference point was set at the center of the circle in the symmetry plane of brake disc. Plane-plane contact was adopted between the friction plate and the brake disc. Lagrange method was used to describe the normal behavior of 
the frictional contact, and used penalty function to describe the tangential behavior between the two parts. For the friction plate, imposed constant pressure $\mathrm{P}=3.426 \mathrm{Mpa}$ on the upper surface of friction plate and limited all DOFs (degree of freedom). For the brake disk, except the rotational DOF at the axial direction, the remaining 5 DOFs were restricted. The rotational inertia force should be imposed with the form of angular velocity at the same time.

\section{Results and Discussion}

\section{Analysis of temperature field in continuous braking condition}
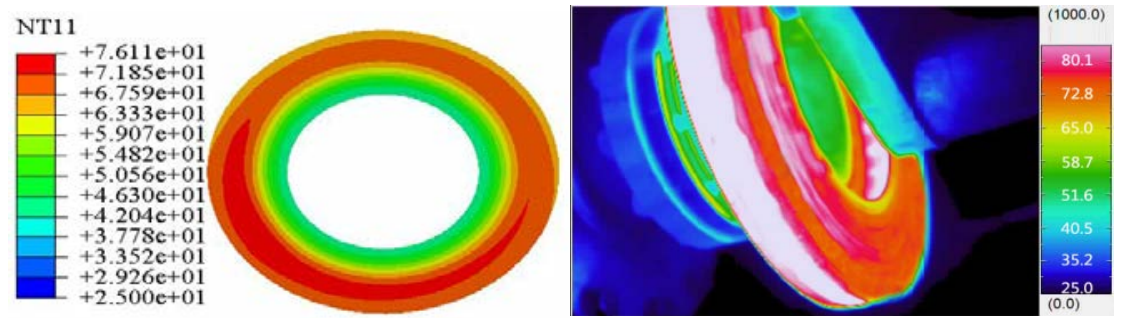

(a) Experiment and Simulation of surface temperature on brake disc at 28.7 seconds
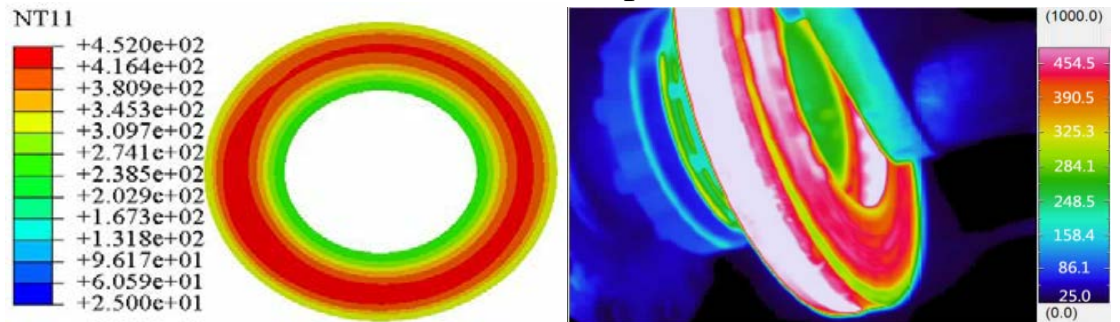

(b) Experiment and Simulation of surface temperature on brake disc at 287 seconds

Fig.3 Experiment and Simulation of surface temperature on brake disc

Under the condition of continuous braking at 28.7s, as shown in Fig 3 (a), is the experiment and simulation comparison about the surface temperature of the brake disc. The highest temperature of the surface in the experiment and simulation are $80.1^{\circ} \mathrm{C}$ and $76.1^{\circ} \mathrm{C}$, and the error between them is $4.99 \%$, which is less than $10 \%$,and it turns out that the result is reasonable. Under the condition of continuous braking at 287s, as shown in Fig 3 (b), is the experiment and simulation comparison of the surface temperature about the brake disc. The highest temperature of the surface in the experiment and simulation are $454.5^{\circ} \mathrm{C}$ and $452^{\circ} \mathrm{C}$, and the error between them is $0.55 \%$, which is less than $10 \%$,and it turns out that the result is reasonable.

Fig. 3 (a) and (b) show that the area of the high temperature is annular and the temperature distributes relatively homogeneous in this area at the end of the first braking; but the area of that decreases obviously and the shape of the area distributes as plaques at the end of the tenth braking.

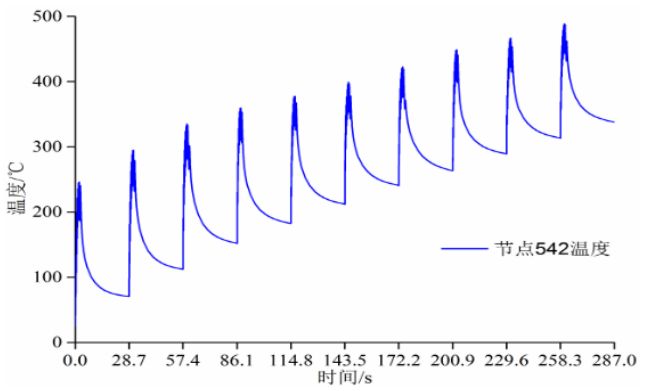

Fig.4 The temperature-time curve under the condition of continuous braking

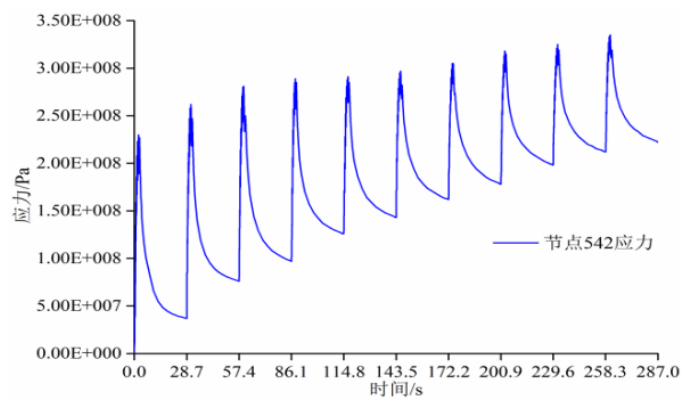

Fig.5 The stress-time curve under the condition of continuous braking

Fig. 4 shows the temperature-time curve under the condition of continuous braking at the node with the highest temperature. It can be seen that the temperature of node rises sharply at the start of braking, and decreases quickly at first and slowly until the minimum after the braking. What's more, the temperature has the same tendency at the latter cycle. Due to the heat can't be released in time during the braking process, the temperature at the surface of brake disk increases every time 
compared with the previous one, and the highest temperature measured at the moment of the end of the tenth time. High frequency of repeated temperature gradient leads to the cyclic tension and pressure, which cause thermal fatigue on the surface of the brake disk and reduce the service life of the brake disk. Therefore, it should be avoided to brake continuously in the process of driving, or it is easy to cause the thermal fatigue, cracks, and even destruction of the brake disk.

\section{Analysis of stress field in continuous braking condition}

Fig. 5 shows that the stress-time curve under the condition of continuous braking at the node with the highest pressure, it can be seen that the curve's shape of stress is similar to the temperature's. The stress of node increases quickly at the beginning of the braking. However, the stress disappears after the braking, and the temperature and thermal stress are gradually reduced, so the comprehensive stress decreases quickly at first and slowly until the minimum. What's more, the stress has the same trend at the latter cycle. Nevertheless, with the passage of the braking time, the pressure on the surface of brake disk increases every time compared with the previous one, and the maximum stress on the annular surface of brake disk exceeds the yield limit of the material(250MPa). What's worse, because of the overloaded stress and alternating action of thermal stress, it is easy to cause fatigue failure, which leads to the fine mesh cracks on the surface of the brake disk.

\section{Analysis of thermal fatigue}

The fine mesh cracks mainly focus on high temperature areas at the annular surface of the brake disk, and there are slightly convex and concave on there. The result is that during the process of friction, the brake disk absorbs a large number of heat and the surface is under pressure, which causes slight deformation. Because the heat disappears during the cooling process, the brake disk wants to recover its original shape and the surface of the brake disk is under tensile force, which leads to thermal stress. Thermal stress can accelerate the oxidation and change the microstructure of materials, and it can also reduce the strength and thermal conductivity of casting. These cases lead to the thermal fatigue, and the most common forms of thermal fatigue are cracks and deformation.

\section{Conclusion}

According to the tensile and compression experiments of the brake disc and the friction plate, the elastic modulus and Poisson's ratio of the two materials can be measured. Using the thermal-mechanical coupling simulation analysis of brake disc and the friction plate, which combines with the experiment of temperature field, the conclusions can be deduced as follows:

(1) In continuous braking condition, because the long time interval between each braking, there is convective heat transferred between friction pairs and air. What's more, the temperature gradient is large in the continuous braking condition, and the continuous braking can generate temperature gradient in the axial direction of the brake disc, which leads to the cyclic tension and pressure and causes the thermal fatigue on the surface of brake disc.

(2) In continuous braking condition, the changeable curve of stress field shows the same distribution of temperature field, the stress increases quickly at the beginning of the braking, and decreases quickly at first and slowly until the minimum after the braking. The pressure on the surface of brake disk increases every time compared with the previous one. When the stress exceeds the yield limit of the material, the surface of the brake disc forms plastic deformation and cracks.

(3) In continuous braking condition, because of the alternating action of temperature and stress, temperature gradient and thermal stress are generated at the axial direction of the brake disk, which results the deformation and accelerates the oxidation and organizational changes of the material. What's worse, it also reduces the strength and thermal conductivity of casting and leads to the thermal fatigue.

\section{Acknowledgement}

In this paper, the research was sponsored by the Project of Natural Science Research Area of Jiangsu Province (Project No. 15KJB460008), the Open Fund Project of Road Vehicles in Jiangsu 
Province Key Laboratory of New Technology Application (Project No. BM20082061505) and Development of Disc Brake for Large Size and High Pressure Vehicle and Development of Test System (Project No. BY2015065-04).

\section{References}

[1] Jintao Zheng. New generation of the disc brake [J]. Automobile \& Parts, 2008 (34):64-65.

[2] Wenqing Zhao. Present research and future prospect of wet disc brake[J]. Transactions of The Chinese Society of Agricultural Machinery,2002,33(2):117-120.

[3] Chenghui Gao, Jianmeng Huang, Youxia Li, Zhi Liu, Yaoliang Chen. Research of the progress of Engineering rough surface contact on friction thermodynamics [A]. Eighth National Conference on Tribology [C]. 2007

[4] Jishan Li, Heping Li, Huting Lin. Resaerch and analysis of the crack on the surface of the brake disc at high speed train [J]. Railway Locomotive 2005 (06):3-5.

[5] Haiyan Zhao, Haiquan Zhang, Xiaohua Tang, Jian Lin, Zhipeng Cai. Finite element analysis of the thermal process of disc brake on rapid train [J]. Journal of Tsinghua University (NATURAL SCIENCE EDITION). 2005 ,45(05):589-592.

[6] Dejian Meng, Lijun Zhang, Zhuoping Yu. Journal of ventilated disc brakes with thermal-mechanical coupling theory modeling and analysis [J]. Journal of Tongji University (Natural Science), 2010 (06):890-897.

[7] Jie Qu, Haifu Su, The life prediction analysis of ventilated brake disc [J]. Mechanical Manufacturing, 2011(06):43-47.

[8] Youfei Chen, Liang Li, Cai Yang, Jian Song. Study on the difference of finite simulation model for brake thermal analysis [J]. Automotive Engineering. 2012 (03):236-240. 